\title{
Knowledge influences attitudes toward vaccination in Romania
}

\author{
DIANA DELEANU ${ }^{1,2,3}$, CARINA PETRICAU ${ }^{1,3}$, POLIANA LERU $^{4}$, IOANA CHIOREAN $^{5}$, \\ ADRIANA MUNTEAN ${ }^{1,3}$, DINU DUMITRASCU ${ }^{6}$ and IRENA NEDELEA ${ }^{1,3}$ \\ ${ }^{1}$ Allergy Department and ${ }^{2}$ Internal Medicine Department, 'Professor Doctor Octavian Fodor' Regional Institute \\ of Gastroenterology and Hepatology, 400162 Cluj-Napoca; ${ }^{3}$ Allergy and Immunology Discipline, \\ 'Iuliu Hatieganu' University of Medicine and Pharmacy, 400012 Cluj-Napoca; ${ }^{4}$ Department of Internal Medicine, \\ Colentina University Hospital, 020125 Bucharest; ${ }^{5}$ Department of Mathematics, 'Babes Bolyai' University, \\ Faculty of Mathematics and Computer Science, 400084 Cluj-Napoca; ${ }^{6}$ Anatomy Discipline, \\ 'Iuliu Hatieganu' University of Medicine and Pharmacy, 400012 Cluj-Napoca, Romania
}

Received August 19, 2019; Accepted September 18, 2019

DOI: $10.3892 /$ etm.2019.8124

\begin{abstract}
Despite proven effectiveness and safety of vaccinations, immunization rates are decreasing across Europe, most countries having suboptimal vaccination coverage, leading to an increase in the number of cases of preventable contagious diseases. In recent years, the number of parents who have refused to vaccinate their children in Romania has decreased substantially, while the number of fatal complications due to measles outbreak is one of the highest in Europe. Since healthcare professionals have been identified as the main advocates for immunization, knowledge and attitudes of medical students and nurses is of particular interest. A cross-sectional survey was carried out on 278 participants, divided into three groups: 183 medical students, 54 nurses and 41 non-medical professionals. The questionnaire included questions on demographics of participants, personal experience with vaccines, knowledge and attitude toward vaccination. The data was collected, centralized and analyzed using statistical methods. The survey was given to the medical students at the beginning of the Immunology course and again at the end, to test whether information received influenced their responses. The study revealed that a great majority of participants were themselves vaccinated $[\mathrm{N}=262(94 \%)]$ and had/or would vaccinate their children $[\mathrm{N}=247(95 \%)]$. Satisfactory overall knowledge about effectiveness and safety concerns was observed, with $98 \%(\mathrm{~N}=270)$ considering vaccines as useful and over $96 \%(\mathrm{~N}=276)$ correctly identified their usefulness. When asked about adverse effects, concerning numbers $[\mathrm{N}=32,(19 \%)]$ of medical students answered incorrectly. After
\end{abstract}

Correspondence to: Dr Carina Petricau, Allergy Department, 'Professor Doctor Octavian Fodor' Regional Institute of Gastroenterology and Hepatology, 400162 Cluj-Napoca, Romania E-mail: carina.petricau@yahoo.com

Key words: vaccination, vaccine hesitancy, vaccine coverage, immunization attitudes, vaccine knowledge the Immunology course, however, there was significant improvement in knowledge on this topic $(\mathrm{P}<0.001)$, correlating with a positive shift in attitude towards current and future vaccines. We predict that better knowledge about vaccines, their efficacy and safety would help build the health provider's confidence in recommending vaccination and thus increased coverage rates.

\section{Introduction}

The value of childhood vaccination as a public health intervention has been demonstrated in the past decades across European countries. In recent years however, despite numerous studies supporting safety and efficacy, a growing number of parents refuse to vaccinate their children. The recent measles outbreaks which continue to spread across Europe are a result of suboptimal vaccination coverage. The latest World Health Organization data on national vaccination coverage for the two doses of Measles, Mumps and Rubella (MMR) vaccine show that only four European countries reported at least a $95 \%$ vaccination rate (1). The downward trend of vaccination coverage in Romania remains consistently low, putting at risk the very young and immune-compromised individuals. The situation is dire; currently the measles outbreak in Romania registered 64 deaths (2). Possible reasons for this decreasing coverage include distortion by the anti-vaccination lobby about safety concerns, lack of perceived benefits, disbelief in the potential burden of vaccine-preventable disease and loss of trust in public health authorities (3). Romania also had a problem in the past with erratic vaccine supply and high-risk groups of impoverished rural communities, mostly of Roma ethnicity, who systematically ignore healthcare measures, including vaccination (4). With these considerations, fear of losing the accomplishments made in combating the morbidity and mortality of infectious disease through vaccines calls for action.

Studies have shown that knowledge provided by healthcare professionals plays a critical role in parents' attitudes toward vaccination $(5,6)$. In Romania, despite physicians' recommendation to vaccinate, a great deal of misinformation by the anti-vaccination movement is causing parents to question 
the validity of timely immunization. However, we predict that better knowledge about vaccines would lead to a shift in positive attitudes and increased coverage rates. Our main goal was to explore the attitude of Romanian medical students, medical professionals (nurses) and non-medical individuals concerning vaccination. Secondarily, we wanted to assess whether knowledge on immunization received during the Immunology course at the 'Iuliu Hatieganu' University of Medicine and Pharmacy (Cluj-Napoca, Romania) influenced the medical students' responses to the questionnaire. The results in this study indicate the need of specific vaccinology training that would better equip healthcare providers to correctly inform the growing number of parents showing mistrust in health authorities.

\section{Materials and methods}

Participants and procedures. A descriptive, explorative cross-sectional study was conducted during October 2017-June 2018 in Cluj-Napoca, Romania. The participants were divided into three groups: medical students attending the 'Iuliu Hatieganu' University of Medicine and Pharmacy, medical staff (nurses) from the Internal Medicine department of 'Professor Doctor Octavian Fodor' Regional Institute of Gastroenterology and Hepatology Cluj-Napoca, and randomly selected non-medical individuals.

The questionnaire was given to the students on the first day of the Immunology course and again on the last day of the course, to nurses and non-medical individuals in the same time period. All responses were anonymous. Informed consent was obtained in writing during the introductory portion of the survey. The study protocol was approved by the Ethics Committee of the 'Iuliu Hatieganu' University of Medicine and Pharmacy Cluj-Napoca.

Study instrument and measures. The study instrument was a questionnaire constructed after conducting a brief literature review. The questionnaire was verified by a panel of Allergy and Immunology specialists for content validity and clarity before reaching the final version. The questionnaire was made up of twenty questions, further divided into four sections:

Demographic information. The participants were asked to report their age, sex, geographic location, education level and occupation.

Personal experience with vaccines. Participants were asked whether they and their children were vaccinated and which vaccination schedule was used (the national schedule, additional optional vaccines, or only partial vaccination).

Immunization knowledge. The questions tested the participant's empirical knowledge about vaccines as well as misconceptions about potential safety concerns.

Attitudes toward vaccination. This last section focused on attitude and the reassurance the participant feels when considering both the traditional as well as the more recently introduced vaccines.

Statistical analysis. Descriptive statistics were used to summarize the variables tested. Pearson's coefficients along with two-tailed significance tests and Spearman's Rho were performed to examine various correlations and differences among the groups. All analysis was performed using the IBM SPSS Statistic software for statistical analysis and $\mathrm{P}<0.05$ was considered statistically significant, while the $\alpha$ level was set at $2.5 \%$ for the two-tailed tests.

\section{Results}

Demographic information. A total number of 278 participants completed the survey, including 183 medical students, 54 medical staff, 41 non-medical professionals. Table I presents the demographic characteristics of the study participants. The median age was 35 years within a range of 19-63 years, with the majority of participants female $[\mathrm{N}=195(70 \%)]$. The largest part of the participants was from an urban area $[\mathrm{N}=254(91 \%)]$. Educational level was mostly represented by participants with college degrees $[\mathrm{N}=224(80 \%)]$, and, as expected, predominantly medical occupation $[\mathrm{N}=237(85 \%)]$.

Personal experience with vaccines. Participants' personal decisions to be vaccinated and have their children vaccinated were evaluated. Results are presented in Table II. Majority of individuals were themselves vaccinated using the National Vaccination program $79 \%(\mathrm{~N}=220)$ and another $15 \%(\mathrm{~N}=42)$ were immunized with supplemental vaccines, for a total of $94 \%$ of participants fully vaccinated. Similarly, when asked if they had or will vaccinate their children, $66 \%(\mathrm{~N}=174)$ would choose the national vaccination program schedule and an additional $28 \%(\mathrm{~N}=73)$ would give supplemental vaccines, for a total of $94 \%$ who personally did or would choose to vaccinate their children.

Immunization knowledge. Participants had a satisfactory overall knowledge about vaccines (effectiveness and safety concerns). Results reported in Table III show that a great majority $[\mathrm{N}=180(98 \%)]$ of participants consider immunization as useful. When asked in what way vaccines are useful, $57 \%(\mathrm{~N}=101)$ of the students and $72 \%(\mathrm{~N}=38)$ of the nurses identified prevention of infectious disease as the only utility of vaccines. The two other options were prevention and or treatment of cancer and that of allergic disease. Only $18 \%(\mathrm{~N}=32)$ of medical students, $13 \%(\mathrm{~N}=7)$ of medical staff and $23 \%(\mathrm{~N}=9)$ of non-medical individuals identified the benefit of vaccination to include prevention of infectious diseases, allergy and neoplastic disorders, accounting for a total of $17 \%(\mathrm{~N}=48)$ of the participants to correctly pinpoint the roles of vaccinations. The analyzed data indicates that nurses are more knowledgeable of correct information regarding adverse effects (questions K3-K5) of vaccines when compared to medical students before the course (average of correct responses 91 vs. 83\%, respectively). Among medical students, $19 \%(\mathrm{~N}=32)$ claimed before the course that adverse effects of vaccines are greater than the risks of not vaccinating and $12 \%(\mathrm{~N}=19)$ considered that adverse effects are greater in number than vaccine benefits. After the course however, students scored higher on the adverse reaction questions, demonstrating statistical significance $(\mathrm{P}<0.01$, two-tailed test and Spearman's rho, $\mathrm{N}=175, \alpha$ level=0.025) when compared to their initial responses (Table IV). Questions 3 and 4, about adverse effects demonstrated the greatest amount of increase in correct answers (12 and 13\%, respectively) after 
Table I. Frequency and percentage distribution of demographic characteristics.

\begin{tabular}{|c|c|c|c|c|}
\hline Variables & $\begin{array}{c}\text { Medical students } \\
\mathrm{N}(\%)\end{array}$ & $\begin{array}{c}\text { Medical staff } \\
\mathrm{N}(\%)\end{array}$ & $\begin{array}{c}\text { Non-medical } \\
\mathrm{N}(\%)\end{array}$ & $\begin{array}{l}\text { Total } \\
\mathrm{N}(\%)\end{array}$ \\
\hline \multicolumn{5}{|l|}{ Age (years) } \\
\hline Range & $19-44$ & $22-53$ & $23-63$ & $19-63$ \\
\hline Median & 21 & 42 & 41 & 35 \\
\hline \multicolumn{5}{|l|}{ Sex } \\
\hline Male & $64(35)$ & $2(4)$ & $17(41)$ & $83(30)$ \\
\hline Female & $119(65)$ & $52(96)$ & $24(59)$ & $195(70)$ \\
\hline Total & $183(100)$ & $54(100)$ & $41(100)$ & $278(100)$ \\
\hline \multicolumn{5}{|l|}{ Geographic area, } \\
\hline Urban & $172(94)$ & $50(93)$ & $32(78)$ & $254(91)$ \\
\hline Rural & $11(6)$ & $4(7)$ & $9(22)$ & $24(9)$ \\
\hline Total & $183(100)$ & $54(100)$ & $41(100)$ & $278(100)$ \\
\hline \multicolumn{5}{|l|}{ Educational level } \\
\hline 4 school grades & $0(0)$ & $0(0)$ & $0(0)$ & $0(0)$ \\
\hline 8 school grades & $0(0)$ & $0(0)$ & $0(0)$ & $0(0)$ \\
\hline High school & $2(1)$ & $16(30)$ & $26(64)$ & $44(16)$ \\
\hline College degree & $179(98)$ & $33(61)$ & $12(29)$ & $224(80)$ \\
\hline Graduate degree & $2(1)$ & $5(9)$ & $3(7)$ & $10(4)$ \\
\hline Total & $183(100)$ & $54(100)$ & $41(100)$ & $278(100)$ \\
\hline \multicolumn{5}{|l|}{ Occupation } \\
\hline Medical & $183(100)$ & $54(100)$ & $0(0)$ & $237(85)$ \\
\hline Non-medical & $0(0)$ & $0(0)$ & $41(100)$ & $41(15)$ \\
\hline Total & $183(100)$ & $54(100)$ & $41(100)$ & $278(100)$ \\
\hline
\end{tabular}

the completion of the Immunology course. The proportion of students who considered infectious diseases to be prevented by vaccination also showed a statistical increase $(\mathrm{P}=0.025$, two-tailed test and Spearman's rho, $\mathrm{N}=175$, $\alpha$ level $=0.025$ ) from $57 \%$ before the course to $62 \%$ after the course. Non-medical profession participants had the lowest scores of the three groups questioned on vaccine understanding, especially for the questions pertaining to adverse reactions. Pearson's correlation tests did not find significant differences between correct answers and educational level of respondents.

When comparing students' responses before the Immunology course and after the course (Table IV), we observed a $7 \%$ increase in number of students who would use new vaccines for themselves and for their children. Also, when asked what they would vaccinate themselves for, $18 \%$ more answered for both cancer and allergic disease after the course.

Attitudes toward vaccination. As presented in Table V, the greatest majority of participants $[\mathrm{N}=246(91 \%)]$ across the groups confirmed their trust in the vaccination process. When asked however, if they would use newly available vaccines for themselves or their children, less than half answered positively (average of $41 \%$ across the groups). Faced with the possibility of being immunized before traveling to a high-risk endemic area, $97 \%$ of all participants said they would get vaccinated. Participants would get vaccinated either to prevent cancer, allergic disease or both (24, 19 and 28\%).

\section{Discussion}

Overall, the participants in our study showed positive attitudes toward vaccination. The fact that a great majority were themselves fully vaccinated and would choose to vaccinate their children indirectly indicates trust in the current immunization process. This positive attitude toward vaccination however, does not translate over to confidence for newer available vaccines. Vaccine hesitancy, as defined by WHO Strategic Advisory Group of Experts (SAGE) of immunization, refers to delay in acceptance or refusal of vaccines despite the availability of vaccination services (7) and was observed in our study as well, specifically when referring to novel vaccines. Only when the risks of not being vaccinated are greater, as in going to an endemic area, were most participants open to receiving additional vaccines. Vaccine-hesitant individuals may refuse some vaccines, but not others, delay vaccination or accept vaccination although doubtful about the practice (7). With the anti-vaccination propaganda infiltrating all social classes and ethnicities in Romania, vaccine hesitant individuals are a very heterogeneous group. Determinants of vaccine hesitancy as identified by SAGE Working group included concerns regarding vaccine safety due to proven adverse events after vaccination or generated by misconceptions conveyed in media, but also religious beliefs, lack of knowledge, including among health professionals, introduction of new vaccines, and mode of vaccine delivery (7). The 
Table II. Frequency and percentage distribution of personal experience with vaccines.

\begin{tabular}{lcccc}
\hline Question/answer choices & $\begin{array}{c}\text { Medical students } \\
\mathrm{N}(\%)\end{array}$ & $\begin{array}{c}\text { Medical staff } \\
\mathrm{N}(\%)\end{array}$ & $\begin{array}{c}\text { Non-medical } \\
\mathrm{N}(\%)\end{array}$ & $\begin{array}{c}\text { Total } \\
\mathrm{N}(\%)\end{array}$ \\
\hline P1. Were you vaccinated? & & & & \\
1. Yes, national vaccination & $142(78)$ & $47(87)$ & $31(76)$ & $220(79)$ \\
2. Yes, supplemental vaccines & $32(17)$ & $2(4)$ & $8(19)$ & $42(15)$ \\
3. I do not know & $9(5)$ & $5(9)$ & $2(5)$ & $16(6)$ \\
4. No & $0(0)$ & $0(0)$ & $0(0)$ & $0(0)$ \\
Total & $183(100)$ & $54(100)$ & $41(100)$ & $278(100)$ \\
P2. Was your child vaccinated? & & & & $174(66)$ \\
1. Yes, national vaccination & $103(59)$ & $43(84)$ & $6(16)$ & $73(28)$ \\
2. Yes, supplemental vaccines & $63(36)$ & $4(8)$ & $2(5)$ & $11(5)$ \\
3. Yes, partial vaccination & $5(3)$ & $0(0)$ & $37(3)$ & $4(1)$ \\
4. No & $3(2)$ & $51(100)$ & $262(100)$ \\
Total & $174(100)$ & &
\end{tabular}

andividuals who do not have a child answered with their future decision if they did have a child.

Table III. Vaccine knowledge questionnaire score distribution.

\begin{tabular}{|c|c|c|c|c|c|}
\hline Question/statement & Score & $\begin{array}{l}\text { Medical students } \\
\text { N }(\%)\end{array}$ & $\begin{array}{l}\text { Medical staff } \\
\quad \mathrm{N}(\%)\end{array}$ & $\begin{array}{l}\text { Non-medical } \\
\quad \mathrm{N}(\%)\end{array}$ & $\begin{array}{l}\text { Total } \\
\mathrm{N}(\%)\end{array}$ \\
\hline K1, Vaccines are useful. & $\begin{array}{l}\text { Correct } \\
\text { Incorrect }\end{array}$ & $\begin{array}{c}180(98) \\
3(2)\end{array}$ & $\begin{array}{c}52(98) \\
1(2)\end{array}$ & $\begin{array}{c}38(95) \\
2(5)\end{array}$ & $\begin{array}{c}270(98) \\
6(2)\end{array}$ \\
\hline $\mathrm{K} 2^{\mathrm{a}}$, Vaccines are useful because & 1 & $101(57)$ & $38(72)$ & $18(45)$ & $157(55)$ \\
\hline they prevent and/or treat: & 2 & $4(2)$ & $0(0)$ & $0(0)$ & $4(1.4)$ \\
\hline 1. Infectious disease & 3 & $0(0)$ & $0(0)$ & $3(8)$ & $3(1)$ \\
\hline 2. Cancer & 4 & $1(0.5)$ & $1(2)$ & $2(5)$ & $4(1.4)$ \\
\hline 3. Allergic disease & 5 & $0(0)$ & $0(0)$ & $0(0)$ & $0(0)$ \\
\hline 4. Vaccines are not useful & 1,2 & $32(18)$ & $4(8)$ & $1(2)$ & $37(13)$ \\
\hline \multirow[t]{3}{*}{ 5. Vaccines are dangerous } & 1,3 & $23(13)$ & $3(5)$ & $7(17)$ & $33(11)$ \\
\hline & 2,3 & $1(0.05)$ & $0(0)$ & $0(0)$ & $1(0.2)$ \\
\hline & $1,2,3$ & $32(18)$ & $7(13)$ & $9(23)$ & $48(17)$ \\
\hline \multirow[t]{2}{*}{$\mathrm{K} 3$, Vaccines can have adverse effects. } & Correct & $141(81)$ & $43(90)$ & $21(54)$ & $205(79)$ \\
\hline & Incorrect & $33(19)$ & $5(10)$ & $18(46)$ & $56(21)$ \\
\hline \multirow{2}{*}{$\begin{array}{l}\text { K4, Adverse effects of vaccines are } \\
\text { greater than the risks of not vaccinating. }\end{array}$} & Correct & $32(19)$ & $6(13)$ & $9(30)$ & $47(20)$ \\
\hline & Incorrect & $134(81)$ & $39(87)$ & $21(70)$ & $194(80)$ \\
\hline \multirow{2}{*}{$\begin{array}{l}\text { K5, Adverse effects of vaccines are greater } \\
\text { in number compared to the benefits of vaccines. }\end{array}$} & Correct & $19(12)$ & $2(4)$ & $10(32)$ & $31(13)$ \\
\hline & Incorrect & $146(88)$ & $44(96)$ & $21(68)$ & $211(87)$ \\
\hline
\end{tabular}

${ }^{\mathrm{a}}$ The correct answers for $\mathrm{K} 2$ are: 1,2,3; ${ }^{\mathrm{b}}$ the answers used on the initial evaluation at the beginning of the Immunology course are recorded.

present study recognized three of the mentioned determinants (vaccine safety, lack of knowledge, and new vaccines) which potentially reflect key factors causing the decline of vaccine coverage in Romania.

As expected, medical students and nurses scored higher on the vaccine knowledge questions when compared to the non-medical individuals. However, our study demonstrated a lack of knowledge about adverse effects of vaccines. A significant number of students considered incorrectly that the adverse effects of vaccines are greater than those generated by not vaccinating and more numerous than the benefits of immunization. A significantly higher percentage of nurses compared to students were able to correctly answer questions on adverse effects, indicating that practicing medicine exposes one to correct information on this topic. As identified in other studies $(7,8)$ we also recognized misinformation about safety concerns and lack of correct information as leading causes of vaccine hesitancy. Ironically, many individuals, including 
Table IV. Knowledge and attitudes of students before and after the course.

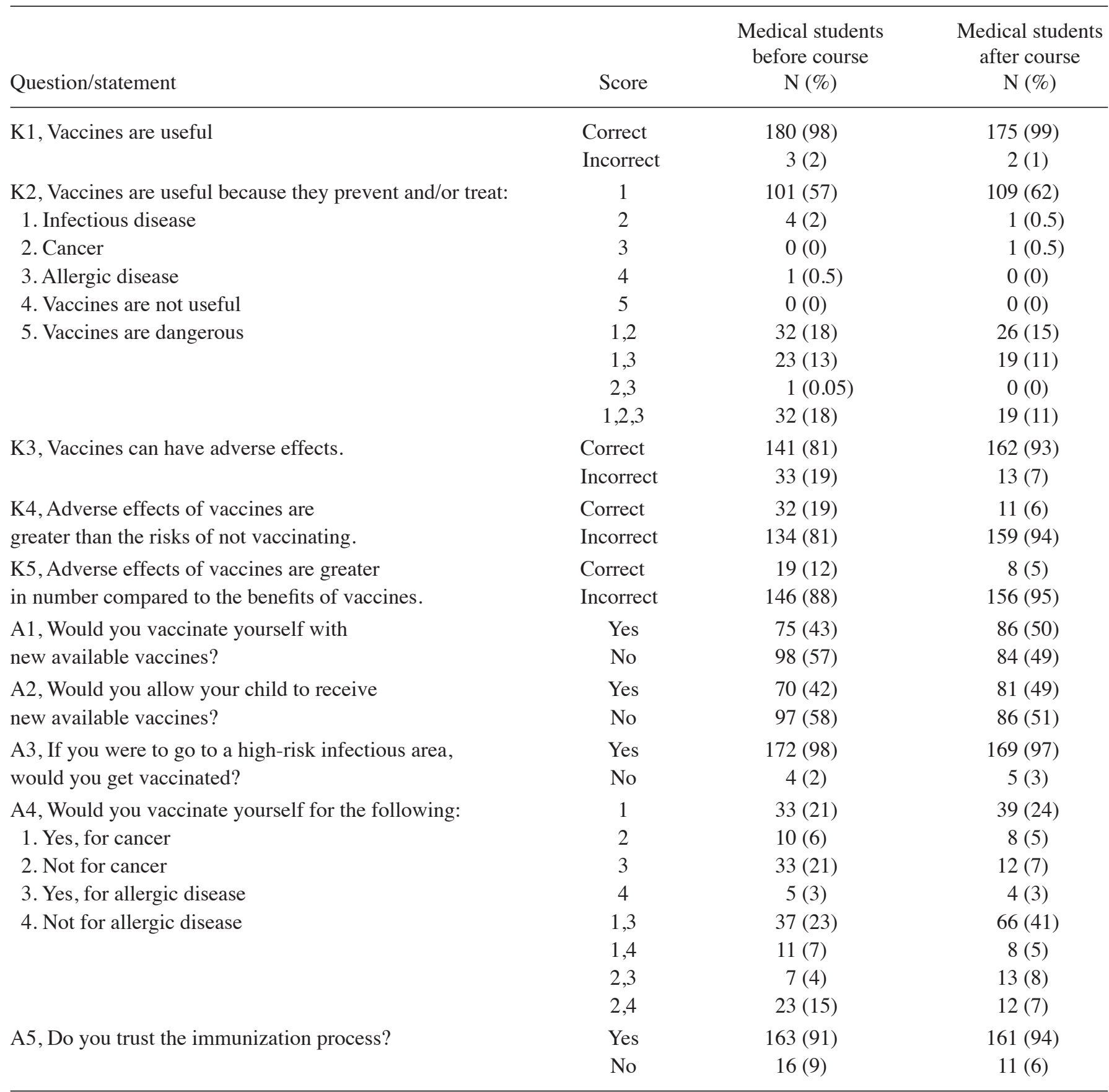

medical providers, have never witnessed the devastating disease prevented by current vaccines, and are therefore more likely to question their necessity, effectiveness and rather highlight their possible adverse effects.

Studies show that health care professionals are the most trusted source of information and have the greatest amount of positive influence regarding vaccination (9-13). In this study, medical students who we consider future physicians and nurses accounted for the healthcare providers who could potentially influence an individual's decision whether or not to vaccinate themselves or their children. In order to effectively influence others, the healthcare professionals themselves must be well equipped with appropriate information. In a study concerning primary care professionals involved in administering childhood vaccines in Barcelona, almost one third of responders felt they did not have sufficient information and training to adequately answer questions vaccine-hesitant parents may have (14). Knowledge about particular vaccines, their efficacy, normal immunological responses and safety would help build the health provider's confidence when recommending vaccination (11,14-18).

Administering the questionnaire before and after the Immunology course allowed us to demonstrate that training health care professionals increases not only knowledge but also attitudes toward vaccination. Student's scores on the vaccine knowledge questions about effectiveness of vaccines and potential adverse effects increased, demonstrating a better understanding after the course. Remarkably, their 
Table V. Distribution of the attitudes toward the immunization score.

\begin{tabular}{lccccc}
\hline Question & & Medical students & Medical staff & Non-medical & Total \\
N & Answer & N $(\%)$ & N $(\%)$ & N $(\%)$ \\
\hline A1, Would you vaccinate yourself with & Yes & $75(43)$ & $20(38)$ & $17(44)$ & $112(42)$ \\
new available vaccines? & No & $98(57)$ & $32(62)$ & $22(56)$ & $152(58)$ \\
A2, Would you allow your child to receive & Yes & $70(42)$ & $17(33)$ & $16(47)$ & $103(41)$ \\
new available vaccines? & No & $97(58)$ & $34(67)$ & $18(53)$ & $149(59)$ \\
A3, If you were to go to a high-risk infectious area, & Yes & $172(98)$ & $51(100)$ & $32(89)$ & $255(97)$ \\
would you get vaccinated? & No & $4(2)$ & $0(0)$ & $4(11)$ & $8(3)$ \\
A4, Would you vaccinate yourself for the following: & 1 & $33(21)$ & $23(49)$ & $3(8)$ & $59(24)$ \\
1. Yes, for cancer & 2 & $10(6)$ & $1(2)$ & $2(5)$ & $13(5)$ \\
2. Not for cancer & 3 & $33(21)$ & $4(9)$ & $10(26)$ & $47(19)$ \\
3. Yes, for allergic disease & 4 & $5(3)$ & $0(0)$ & $1(3)$ & $6(2)$ \\
4. Not for allergic disease & 1,3 & $37(23)$ & $13(28)$ & $17(45)$ & $67(28)$ \\
& 1,4 & $11(7)$ & $0(0)$ & $0(0)$ & $11(5)$ \\
& 2,3 & $7(4)$ & $2(4)$ & $1(3)$ & $10(4)$ \\
& 2,4 & $23(15)$ & $4(8)$ & $4(10)$ & $31(13)$ \\
A5, Do you trust the immunization process? & Yes & $163(91)$ & $48(92)$ & $35(90)$ & $246(91)$ \\
& No & $16(9)$ & $4(8)$ & $4(10)$ & $24(9)$ \\
\hline
\end{tabular}

${ }^{a}$ The answers used on the initial evaluation at the beginning of the Immunology course are recorded here.

willingness to use newly available vaccines in the future also increased, indicating added confidence in vaccines supported by a good understanding of the mechanisms behind them. It is our belief that medical education curricula in Romania, as well as that of all European countries should be revised to include additional training in vaccinology, to better prepare future physicians with accurate knowledge on the topic of immunization.

The Summit of Independent European Vaccination Experts (SIEVE) have come up with possible strategies to improve vaccination coverage, targeting not only health care professionals but also the general public (15). Despite the fact that media has had undesirable effects in this context by indirectly supporting the anti-vaccination propaganda, a strong relationship between medical experts and journalists could use media to promote vaccination and inform the public $(15,17)$. The public must receive accurate, reliable, and positive information on the benefits of vaccines and minimal risks associated with their use $(10,15)$. Healthcare providers need prompt access to appropriate, up-to-date material. One successful initiative is INFO-VAC, which is an interactive information system on vaccines for general practitioners and pediatricians in Switzerland $(15,19)$. Because parental concerns are varied and parent-physician interaction is limited, lack of adequate time to communicate appropriately could also be an impediment worth considering $(15,20)$. Centralized databases would benefit both the healthcare providers and parents with scheduled reminders in order to increase vaccination uptake (15). Vaccination opportunities should extend past the traditional environment for immunization, giving patients the occasion to be vaccinated in hospitals, in out-patient clinics, and even during home visits (15). The suggested strategies to improve vaccine coverage are great approaches for epidemiological professionals responsible for vaccination in all European countries to consider.

Our results must be interpreted in the context of methodological limitations. First, the majority of our participants were medical students and nurses and thus we cannot extrapolate the data to represent the majority of Romanian population. Secondly, vaccination coverage in this study is much higher than the official percentage according to the Romanian National Institute of Public Health, which states that Romania is still more than $10 \%$ under the minimum coverage rate (2). Thirdly, medical students, not medical doctors, were surveyed which could inappropriately portray a lack of knowledge about vaccines within the medical community.

In conclusion, the present study revealed a generally positive attitude of Romanian medical students, nurses and non-medical participants towards vaccination. Considering the growing trend of vaccine hesitancy in all European countries, and especially in Romania, this study established the education of medical students and subsequently of other medical professionals as an important contribution in the struggle to increase vaccination coverage. By introducing Immunology courses that cover the subject of vaccines, gaps in knowledge will be thoroughly covered, attitudes will be positively influenced and confidence alongside willingness to promote vaccinations will greatly increase. Additionally, the strategies suggested by SIEVE will further spread vaccination uptake and maintenance of coverage.

\section{Acknowledgements}

We would like to acknowledge Dr Denisa Cimpean for her invaluable contribution in gathering information for the database. 


\section{Funding}

No funding was received.

\section{Availability of data and materials}

The datasets used and analyzed during the current study are available from the corresponding author upon request.

\section{Authors' contributions}

DDe, PL, AM and DDu were involved in conceptualization of the study design. CP and IN were involved in data acquisition, analysis and interpretation. IC was involved in the interpretation of data and statistical analysis. DDe, CP and IN were major contributors in drafting the manuscript. All authors revised and approved the manuscript and agree to be accountable for all aspects of the research in ensuring that the accuracy or integrity of any part of the work are appropriately investigated and resolved.

\section{Ethics approval and consent to participate}

The study protocol was approved by the Ethics Committee of the 'Iuliu Hatieganu' University of Medicine and Pharmacy (Cluj-Napoca, Romania). Written informed consent was signed by all the participants in the study.

\section{Patient consent for publication}

Not applicable.

\section{Competing interests}

The authors declare that they have no competing interests.

\section{References}

1. World Health Organization: Measles-containing vaccine 2nd dose - reported estimates of MCV2 coverage (Internet). Geneva: WHO; 2018 (cited 2 April 2019) Available from: http://apps.who. int/immunization_monitoring/globalsummary/timeseries/tscoveragemcr2.html.

2. National Institute of Public Health Romania: Situatia rujeolei in Romania (Measles situation reports, Romania) (Internet). 2019 (cited 2 April 2019). Available from: http://www.cnscbt.ro/ index.php/informari-saptamanale/rujeola-1/1169-situatia-rujeole i-in-romania-la-data-de-29-03-2019/file.

3. Black S and Rappuoli R: A crisis of public confidence in vaccines. Sci Transl Med 2: 61mrl, 2010.

4. Duval L, Wolff FC, McKee M and Roberts B: The Roma vaccination gap: Evidence from twelve countries in Central and South-East Europe. Vaccine 34: 5524-5530, 2016.
5. Kelley CA, Velazco CS, Delaney TV, Bensimhon A, Huang KN, Jarvis PR, Jolin JS, Schaberg KB, Burke M, Finley C, et al: Factors contributing to suboptimal rates of childhood vaccinations in Vermont. J Child Health Care 19: 558-568, 2015.

6. Tickner S, Leman PJ and Woodcock A: Factors underlying suboptimal childhood immunisation. Vaccine 24: 7030-7036, 2006.

7. Dube E, Gagnon D, Nickels E, Jeram S and Schuster M: Mapping vaccine hesitancy - Country-specific characteristics of a global phenomenon. Vaccine 32: 6649-6654, 2014.

8. Cvjetkovic SJ, Jeremic VL and Tiosavljevic DV: Knowledge and attitudes toward vaccination: A survey of Serbian students. J Infect Public Health 10: 649-656, 2017.

9. Herzog R, Álvarez-Pasquin MJ, Díaz C, Del Barrio JL, Estrada JM and Gil Á: Are healthcare workers' intentions to vaccinate related to their knowledge, beliefs and attitudes? A systematic review. BMC Public Health 13: 154, 2013.

10. Navarro Alonso JA, Bernal González PJ and Niguez Carbonell JC: Analysis of factors influencing vaccine uptake: Perspective from Spain. Vaccine 20 (Suppl 1): S13-S15, 2001.

11. Paterson P, Meurice F, Stanberry LR, Glismann S, Rosenthal SL and Larson HJ: Vaccine hesitancy and healthcare providers. Vaccine 34: 6700-6706, 2016

12. Boda D, Docea AO, Calina D, Ilie MA, Caruntu C, Zurac S, Neagu M, Constantin C, Branisteanu DE, Voiculescu V, et al: Human papilloma virus: Apprehending the link with carcinogenesis and unveiling new research avenues (Review). Int J Oncol 52: 637-655, 2018

13. Boda D, Neagu M, Constantin C, Voinescu RN, Caruntu C, Zurac S, Spandidos DA, Drakoulis N, Tsoukalas D and Tsatsakis AM: HPV strain distribution in patients with genital warts in a female population sample. Oncol Lett 12: 1779-1782, 2016.

14. Picchio CA, Carrasco MG, Sagué-Vilavella M and Rius C: Knowledge, attitudes and beliefs about vaccination in primary healthcare workers involved in the administration of systematic childhood vaccines, Barcelona, 2016/17. Euro Surveill 24: 1800117, 2019.

15. Schmitt HJ, Booy R, Aston R, Van Damme P, Schumacher RF, Campins M, Rodrigo C, Heikkinen T, Weil-Olivier C, Finn A, et al: How to optimise the coverage rate of infant and adult immunisations in Europe. BMC Med 5: 11, 2007.

16. Solomon I, Voiculescu VM, Caruntu C, Lupu M, Popa A, Ilie MA, Albulescu R, Caruntu A, Tanase C, Constantin C, et al: Neuroendocrine factors and head and neck squamous cell carcinoma: An affair to remember. Dis Markers 2018: 9787831, 2018.

17. Lewis $\mathrm{J}$ and Speers T: Misleading media reporting? The MMR story. Nat Rev Immunol 3: 913-918, 2003.

18. Neagu M, Caruntu C, Constantin C, Boda D, Zurac S, Spandidos DA and Tsatsakis AM: Chemically induced skin carcinogenesis: Updates in experimental models (Review). Oncol Rep 35: 2516-2528, 2016.

19. Siegrist C, Desgrandchamps D, Heininger U and Vaudaux B: How to improve communication on vaccine issues at the national level? INFOVAC-PED: An example from Switzerland. Vaccine 20 (Suppl 1): S98-S100, 2001.

20. Davis TC, Fredrickson DD, Arnold CL, Cross JT, Humiston SG, Green KW and Bocchini JA Jr: Childhood vaccine risk/benefit communication in private practice office settings: A national survey. Pediatrics 107: E17, 2001. 